\title{
The cause and consequence of ontogenetic changes in social aggregation in New Zealand spiny lobsters
}

\author{
Mark J. Butler IV ${ }^{1, *}$, Alistair B. MacDiarmid ${ }^{2}$, John D. Booth ${ }^{2}$ \\ ${ }^{1}$ Department of Biological Sciences, Old Dominion University, Norfolk, Virginia 23529-0266, USA \\ ${ }^{2}$ National Institute for Water and Atmospheric Research, PO Box 14-901, Kilbirnie, Wellington, New Zealand
}

\begin{abstract}
Ontogenetic changes in the behavior, spatial distribution, or habitat use of a species are presumably adaptations to ecological forces that differ in their effect on various life stages. The New Zealand rock lobster Jasus edwardsii is one of several species of spiny lobster that exhibits dramatic ontogenetic shifts in sociality and spatial distribution, and we tested whether such changes are adaptive. We first surveyed several natural populations of $J$. edwardsii to document size-specific differences in aggregation. To determine if chemical cues discharged by conspecifics promote aggregation of certain ontogenetic stages, we tested the responsiveness of lobsters of 3 ontogenetic stages (early benthic juvenile, juvenile, and subadult) to the chemical cues produced by conspecifics of different sizes. Finally, we tethered lobsters of different ontogenetic stages alone and in groups to test the effect of lobster size and aggregation on mortality. Our results offer compelling evidence that pre-reproductive $J$. edwardsii undergo an ontogenetic change in sociality that alters their spatial distribution and survival. Our field surveys show that $J$. edwardsii are solitary as early benthic juveniles and become social and aggregate as they grow larger. We then demonstrate, using laboratory experiments, that there is a sizespecific increase in the response of pre-reproductive $J$. edwardsii to the chemical cues of larger conspecifics which facilitates these ontogenetic changes in aggregation. Finally, our tethering results confirm that this change in social condition is selectively advantageous: aggregation does not increase the survival of small lobsters, but larger lobsters survive better in groups. Thus, in this study we demonstrate the linkage between ontogenetic changes in the spatial distribution of a species, the behavioral process that creates the pattern, and the selective advantage conferred by these developmental changes.
\end{abstract}

KEY WORDS: Spiny lobster · Rock lobster · Jasus edwardsii - Ontogeny · Sociality · Aggregation Predation

\section{INTRODUCTION}

Social aggregation is widespread among marine animals. It occurs in mammals and fish of many kinds (Pitcher 1992), and in a diversity of invertebrate groups including: squid, krill, molluscs, (Catterall \& Poiner 1983, Stoner \& Ray 1993), decapod crustaceans (Atema \& Cobb 1980, among others), and others (Ritz 1994). Social aggregations develop because of mutual attraction among conspecifics and the evolution of cooperative group behavior that enhances individual defense, foraging, movement, or reproduction (Wilson 1975).

•E-mail: mbutler@odu.edu
Social groups differ from other aggregations that arise indirectly in response to patchy resources. This is the case, for example, where settlement on limited substrates or foraging on concentrated patches of food results in clusters of animals. Social aggregation can be beneficial because it can increase vigilance and group defense against predators, thus reducing the per capita probability of mortality from predation, and possibly improving detection of food resources (see reviews by Bertram 1978, Pitcher et al. 1982, Pulliam \& Caraco 1984, Lima \& Dill 1990). However, the benefits of aggregation may be counter-balanced by increases in intraspecific competition for food resources (Milinski \& Parker 1991), or by increased mortality caused by 
predators that also forage in groups and thus locate clumped prey more easily (Major 1978). Aggregation can also be deleterious for cryptic or camouflaged animals if it makes them more conspicuous (Harvey \& Greenwood 1978, Owen 1980, Dukas \& Clark 1995, Butler et al. 1997). Moreover, the ecological conditions favoring social aggregation are not static and vary with changes in predator density, resource (food or habitat) availability, and individual size or developmental stage (i.e. ontogeny; Wilson 1975, Trivers 1985)

Ontogenetic changes in social aggregation often take 1 of 2 forms. Social aggregations are common during early life stages when individuals are small, vulnerable, and inexperienced. Aggregation often diminishes among subadults, but can reappear at adulthood for reproductive purposes. Less common are species that are solitary as juveniles and aggregated as prereproductive adolescents or subadults. This type of ontogenetic behavioral pattern can develop, for example, where aggregation by defenseless juveniles increases their detection by predators and thus their probability of mortality (Tinbergen et al. 1967, Treisman 1975, Dukas \& Clark 1995, Butler et al. 1997). Cryptic behavior and camouflaged coloration are beneficial to juveniles under these conditions. Spiny lobsters (Crustacea; Palinuridae) are 1 group of marine organisms that exhibit this pattern; most species appear to be solitary when young and then aggregate as they grow larger (Herrnkind et al. 1994, Lipcius \& Cobb 1994, Phillips \& Booth 1994)

Spiny lobsters have complex life cycles involving several ontogenetic stages and habitats. Their larvae are typically planktonic for 6 to $18 \mathrm{mo}$ and then metamorphose into a non-feeding puerulus postlarval stage lasting several weeks. Postlarvae swim and are advected nearshore where they settle in shallow, architecturally complex benthic habitats (Herrnkind et al. 1994). There are no data from which it can be discerned whether spiny lobster larvae or postlarvae actively aggregate or are social, although postlarvae periodically settle in dense aggregations in natural habitats (Booth 1979. Jernakoff 1990, Norman et al. 1994) and on artificial collectors (Phillips \& Booth 1994). Newly settled early benthic juvenile $\left(E B J_{i}=\right.$ postpuerulus; see Lavalli \& Lawton 1996) lobsters live in holes or dense vegetation, are solitary, and at least 1 species (Caribbean spiny lobster Panulirus argus is non-aggregative at this stage (Herrnkind et al. 1994, Childress \& Herrnkind 1996). As they grow through adulthood, lobsters inhabit increasingly larger crevices, which for some species results in a marked shift in their choice of habitat and pattern of aggregation (Berrill 1975, Cobb 1981, Herrnkind \& Butler 1986, Herrnkind \& Lipcius 1989, Trendall \& Bell 1989, Eggleston et al. 1990, Glaholt 1990). Yet, only 1 recent study (Ratchford \& Eggleston 1998) has linked these ontogenetic changes in aggregation with the proximate processes that promote them, and no study has offered evidence that such changes influence survival or fecundity.

Findings from several unrelated studies suggest that there are distinct ontogenetic differences in aggregation of Jasus edwardsii, the New Zealand rock or spiny lobster. All stages are found in rocky habitats; juveniles and adults tend to aggregate in particular dens (MacDiarmid 1991, 1994, MacDiarmid et al. 1991), whereas EBJ occupy small shelters individually (Kensler 1966, Booth 1979, Booth \& Bowring 1988, Booth et al. 1991). This increase in the patchiness of lobsters with size may be due to: (1) ontogenetic changes in behavior that enhance social aggregation of larger lobsters, (2) differential mortality of lobsters among shelter locations that creates patches of survivors, or (3) differences in the spatial distribution of crevices of different sizes. If the first hypothesis is true and $J$. edwardsii actively congregate as large juveniles and adults, then they must have some means of locating one another. Chemical (odor) detection is a likely mechanism; it is used by the adults and subadults of other species, notably Panulirus interruptus (ZimmerFaust et al. 1985, Zimmer-Faust \& Spanier 1987) and $P$. argus (Ratchford \& Eggleston 1998). However, it is not known whether $J$. edwardsii responds to chemical cues, or if the use of chemical cues varies among the life stages of this or any species of lobster.

Thus, in this study we sought to: (1) determine whether the aggregative behavior of Jasus edwardsii varied among ontogenetic stages, (2) investigate behavioral mechanisms that might create changes in aggregation, and (3) examine the potential adaptive value of ontogenetic changes in aggregation. We first characterized the natural spatial distribution of non-reproductive lobsters of 3 natural ontogenetic stages: EBJ (<20 mm carapace length; CL), juveniles (20 to $40 \mathrm{~mm}$ CL), and subadults ( 40 to $85 \mathrm{~mm}$ CL). In the laboratory, we then determined if chemical cues play a role in establishing the spatial patterns we observed in the field. Finally, we evaluated whether aggregation of lobsters of different ontogenetic stages in natural dens alters their short-term survival and thus has adaptive significance under present ecological conditions. Our results offer compelling evidence that juvenile $J$. edwardsii undergo an ontogenetic change in sociality that alters their spatial distribution and enhances their survival.

\section{METHODS AND MATERIALS}

Ontogenetic changes in the spatial distribution of natural populations. To document ontogenetic changes in the spatial distribution of Jasus edwardsii, we first 


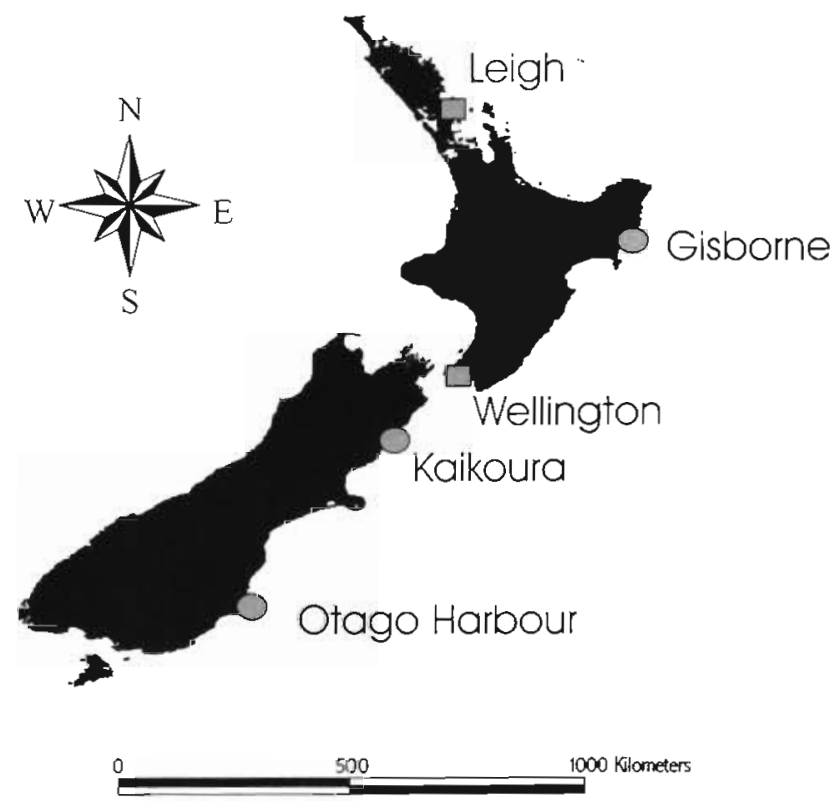

Fig. 1. Location of sites along the coast of New Zealand where lobster surveys and tethering experiments were conducted. Surveys were conducted at all the sites shown; tethering studies were only conducted at Leigh and Wellington

conducted 2 separate observational studies. In the first study we documented the degree of aggregation of various size classes of lobsters (EBJ, juveniles, subadults) on a single occasion in natural habitats at several sites along the east coast of New Zealand (Fig. 1). To better assess the aggregation patterns of EBJ, which were not well represented in our largescale sampling, we conducted a second study where we focused our sampling effort at a single location (Gisborne Harbor) and recorded the distribution of EBJ there repeatedly over many months. This sampling protocol also allowed us to examine whether temporal changes in postlarval settlement density altered the subsequent distribution and abundance of postlarvae and EBJ that had recently settled.

Large-scale observations of lobster distributions. We determined the spatial distribution and abundance of lobsters of all sizes on shallow (1 to $15 \mathrm{~m}$ ) rock reefs at 4 locales spread along approximately $1000 \mathrm{~km}$ of New Zealand's eastern coastline on both the North and South Islands. From north to south, those locales were: (1) the Cape Rodney-to-Okakari Point Marine Reserve on the northeast coast of the North Island at Leigh (Leigh), (2) the south coast of the North Island near Wellington Harbor (Wellington), (3) the Kaikoura Peninsula on the northeast coast of the South Island (Kaikoura), and (4) Otago Harbor on the southeast coast of the South Island (Otago; Fig. 1).

Two sites 100 to $500 \mathrm{~m}$ apart were surveyed at each locality. At each site, 5 replicate $50 \mathrm{~m} \times 10 \mathrm{~m}\left(500 \mathrm{~m}^{2}\right)$ quadrats were demarcated by divers using tape measures. These large quadrats were in turn subdivided into twenty $5 \mathrm{~m} \times 5 \mathrm{~m}\left(25 \mathrm{~m}^{2}\right)$ subplots. Divers then searched within each of the $25 \mathrm{~m}^{2}$ subplots for lobsters dwelling in the crevices within the rock reef. We recorded the number, size (to nearest $5 \mathrm{~mm}$ ), and sex of all lobsters observed in each group. Thus, the abundance and pattern of aggregation of lobsters of all sizes were collected from a total of $80025 \mathrm{~m}^{2} \mathrm{sub}$ plots ( $=20000 \mathrm{~m}^{2}$ area that was surveyed by divers) from 4 locales scattered along the east coast of New Zealand.

These data were partitioned into 3 data sets to allow us to describe separately the size-specific distribution of EBJ, juveniles, and subadult lobsters. Data collected from the $25 \mathrm{~m}^{2}$ subplots were then used to describe the distribution of lobsters in crevices because they were most likely to yield the information we desired on small-scale aggregation patterns. However, since these data were obtained from adjoining $25 \mathrm{~m}^{2}$ subplots created from the subdivision of $500 \mathrm{~m}^{2}$ quadrats, data collected from the small subplots may not be independent, even if the larger quadrats were. Therefore, we present only descriptive plots of the frequency with which lobsters of different sizes aggregate (see Hurlbert 1984, Heffner et al. 1996). We did not attempt to use inferential statistics or spatial indices intended for analysis of randomly collected data. Nonetheless, these plots are useful for examining whether lobsters of different sizes tend to dwell solitarily in crevices or co-inhabit crevices with conspecifics.

Small-scale EBJ lobster distribution and settlement at Gisborne Harbor. Because small EBJ lobsters were underrepresented in our large-scale surveys, we used another data set to more thoroughly investigate their spatial dispersion. We sampled postlarvae (= pueruli) and EBJ that were dwelling in holes on vertical rock faces beneath the 'No. 7' Wharf at Gisborne Harbor on the east coast of the North Island of New Zealand (Fig. 1). The Gisborne Wharf is approximately $200 \mathrm{~m}$ long and beneath it lies a vertical rock wall about $2 \mathrm{~m}$ high from its top edge (defined by the mean low tide) to its bottom edge where it meets a gently sloped, silty bottom. Concrete pilings that support the wharf are set into the wall at approximately $3 \mathrm{~m}$ intervals, thus forming about 60 discrete rock faces that are approximately $6 \mathrm{~m}^{2}$ in area and separated by the $0.5 \mathrm{~m}$ wide concrete pilings.

There is little algal growth on the rock wall because the wharf shades it, but it is covered by encrusting sponges, ascidians, and tunicates. Importantly, the wall is also peppered with innumerable small holes excavated by burrowing pholad molluscs. It is in these clam burrow holes that postlarval Jasus edwardsii settle and EBJ reside under the wharf. The dimensions of 
the holes on the Gisborne Wharf wall resemble those used by newly settled Panulirus japonicus EBJ in Japan (Norman et al. 1994). We estimate that within our sampling quadrats, unoccupied holes were at least an order of magnitude more numerous in our sample quadrats $\left(0.25 \mathrm{~m}^{2}\right)$ than holes occupied by lobsters. They were so abundant that they were unlikely to have influenced the distribution of lobsters at even the smallest spatial scale that we measured $(10 \mathrm{~cm} \times$ $10 \mathrm{~cm}$ ). However, the holes were only large enough to house a single postlarvae or EBJ, so aggregations could only occur if lobsters occupied adjacent holes.

We collected 2 separate sets of distributional data on postlarvae and EBJ: (1) a long-term, large spatial scale survey and (2) a short-term, small spatial scale survey. Our long-term data set included 29 monthly surveys (April to November 1993; March to December 1994; January to December 1995; January, March, and April 1996) of at least 9 and up to 25 separate rock faces out of the 60 available. During each survey, a diver carefully scanned each $6 \mathrm{~m}^{2}$ rock face and recorded the number of lobsters found dwelling in holes. Each rock face is a natural sampling unit of nearly equal size, so we computed estimates of lobster density (mean \pm 1 $\mathrm{SD}$ ) and spatial dispersion. We used the Standardized Morisita's Index to describe spatial dispersion because this index is unbiased by density or sample size (Myers 1978). This index ranges from +1.0 to -1.0 . A random distribution yields a value of 0 , positive values indicate a clumped or patchy distribution, whereas uniform patterns produce a negative value.

Commensurate with these long-term surveys, we also monitored the monthly settlement of postlarvae into 5 standard crevice collectors (Booth \& Tarring 1986, Phillips \& Booth 1994) deployed under the wharf on the bottom in front of the rock wall. These data allowed us to compare the correlation between the number of postlarvae settling in collectors and the subsequent spatial distribution of settled pueruli and EBJ (using Standardized Morisita's Index, described abovel in holes on the rock face.

Our short-term data set covered the period from March to December 1995 (10 mo). In these surveys, the position of each puerulus or EBJ on 10 of the rock faces was recorded in more detail. To do this, we established a permanent reference rope line near the top of the 10 rock faces ( $29.5 \mathrm{~m}$ wide) and then used a $0.5 \mathrm{~m} \times 0.5 \mathrm{~m}$ $\left(0.25 \mathrm{~m}^{2}\right)$ PVC quadrat, divided by string into $10 \mathrm{~cm} \times$ $10 \mathrm{~cm}$ subplots, to record the number of lobsters that divers observed in each $0.01 \mathrm{~m}^{2}$ portion along the top $1 \mathrm{~m}$ of the rock faces (2950 $0.01 \mathrm{~m}^{2}$ subplots surveyed $=29.5 \mathrm{~m}^{2}$ total area). To document daily patterns of lobster residency within holes on a rock face, we marked the position of each postlarvae or EBJ with individually numbered nail tags driven into the rock near the occupied hole. We also tagged a subsample of the lobsters we found with color-coded wire antennae tags, or by clipping the tips of their antennae. We did so without removing the lobsters from their holes in order to minimize disturbance to the lobsters. We then resurveyed these 10 rock faces for the next 2 to $3 \mathrm{~d}$ and noted any changes in the occupancy of holes by lobsters. The results of these surveys (see 'Results') suggest that our procedures did not disturb lobsters enough to drive them from their shelters and hence alter their distribution.

The design of our short-term surveys permitted us to examine the distribution of postlarvae and EBJ dwelling in holes at several spatial scales. Since our $0.25 \mathrm{~m}^{2}$ sampling quadrats were laid end to end across the 10 rock faces and were subdivided into twenty-five $0.01 \mathrm{~m}^{2}$ subquadrats, they essentially constituted a series of ten $0.01 \mathrm{~m}$ wide belt transects (or string of adjacent quadrats) stretching across the rock faces. We used these data from the first day of each monthly sampling and Hill's Two Term Local Quadrat Variance Method (TTLQV; Hill 1973) to examine the pattern of postlarvae and EBJ dispersion across several spatial scales. The TTLQV method yields estimates of variance using increasingly larger quadrats along a transect, in our case, for quadrats from $0.01 \mathrm{~m}^{2}$ to $1 \mathrm{~m}^{2}$. Variances are typically plotted against quadrat size, and pronounced peaks in the variance indicate clumping at the corresponding quadrat size. Thus, differences in spatial dispersion can be evaluated simultaneously at several scales, which is not possible when random quadrats are used.

Laboratory tests of aggregation cues. Experimental trials: We used a set of laboratory experiments to address 2 related questions: (1) does aggregative behavior vary among ontogenetic stages (e.g. EBJ, juvenile, subadult)? and (2) if aggregation occurs, do chemical cues - as opposed to visual or auditory cues-play a role in the process? To answer these questions, individual lobsters of 1 of the 3 ontogenetic groups were permitted to choose among 3 alternative shelters: (1) a shelter with no specific lobster cues (shelter treatment), (2) a shelter supplied with water from a head tank containing similar sized conspecifics (shelter + chemical cue treatment), or (3) a shelter containing 2 lobsters of a similar size as the test lobster, but isolated from the rest of the experimental arena by a transparent plastic barrier (shelter + decoys treatment). To control for treatment artifacts, every shelter was physically identical, and each received water flow from a separate head tank. The 'shelter' and 'shelter + decoys' treatments received seawater without conspecific cues. Forty-eight replicates were run on EBJ and 24 replicates each on juvenile and subadult lobsters. All lobsters were used only once in the study. 


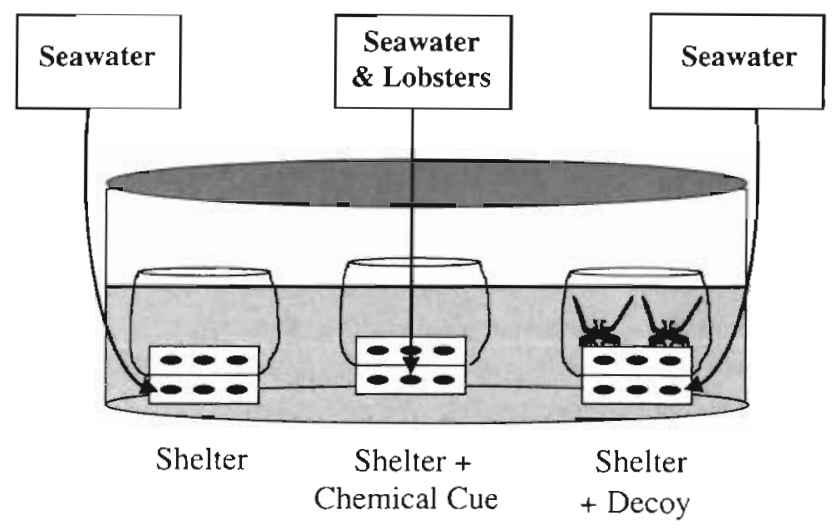

Fig. 2. Diagram of the laboratory set-up designed to test for an aggregative response by a single lobster in 1 of 3 ontogenetic stages (EBJ, juveniles, subadults) released into an experimental tank with 3 shelters offering either: (1) shelter (Shelter treatment), (2) shelter plus the chemical scent of conspecifics (Shelter + Chemical Cue treatment) or (3) shelter plus the visual or auditory cues produced by conspecific decoys enclosed in a plastic bag (Shelter + Decoy treatment). Four of these experimental arenas were constructed and ran simultaneously

Our experiments were carried out from April to June 1995 in a large wet laboratory at the National Institute for Water and Atmospheric Research in Wellington, New Zealand. Water temperature during this period ranged from 12 to $15^{\circ} \mathrm{C}$ and the photoperiod in the laboratory was set at $12 \mathrm{~L}: 12 \mathrm{D}$. The experiments were conducted in 4 round, plastic experimental tanks, or 'arenas' ( $1.6 \mathrm{~m}$ diameter $\times 0.5 \mathrm{~m}$ tall), fitted with separate flow-through seawater systems (Fig. 2). Each arena received filtered seawater through water lines connected to 3 separate head tanks $(20 \mathrm{~cm} \times 33 \mathrm{~cm} \times$ $55 \mathrm{~cm}$ ), which in turn received seawater from the main laboratory flow-through system. Three water lines entered each experimental arena and were attached to 1 of 3 separate lobster shelters (Fig. 2). The water flow into each shelter was $0.2 \mathrm{l} \mathrm{min}^{-1}$, for a combined flow rate of $0.6 \mathrm{l} \mathrm{min}^{-1}$ into each arena. In one head tank we held captive lobsters of a certain size to serve as the source of our chemical cue treatment. For trials with EBJ, juveniles, and subadults, we placed 12,6, and 3 (respectively) similar-sized individuals into the head tank that dispensed the chemical effluent. We placed more juveniles than subadults in the head tanks to keep the biomass in the head tanks similar among treatments. We used as many EBJ in the head tanks as was logistically feasible, but this was fewer than what would be necessary to equal the lobster biomass in the juvenile and subadult treatments. However, preliminary trials (see below: 'Testing for artifacts') revealed that our experiments with EBJ would be unaffected by this difference, since EBJ are unresponsive to water conditioned by other lobsters, regardless of the biomass used to create the chemical signal.

Three shelters, separated by about $120 \mathrm{~cm}$, were positioned uniformly along the edge of each experimental arena. The size of the shelter we used in each experiment differed depending on the size of the lobsters we were testing. Two bricks $(235 \mathrm{~mm} \times 74 \mathrm{~mm} \times$ $94 \mathrm{~mm}$ ), each with 10 holes ( $22 \mathrm{~mm}$ diameter), and stacked one upon the other, served as shelter suitable for occupation by EBJ. Two stacked concrete partition blocks ( $392 \mathrm{~mm} \times 192 \mathrm{~mm} \times 141 \mathrm{~mm}$ ) with oblong holes ( $80 \mathrm{~mm}$ high $\times 130 \mathrm{~mm}$ wide) served as a shelter in tests with the 2 larger lobster size classes (juveniles and subadults).

In all experiments, regardless of the shelter type, a large, transparent plastic bag $(0.1 \mathrm{~mm}$ thick) filled with seawater and open to the atmosphere at the top, enclosed the top shelter block. When an individual shelter was to receive lobsters to serve as 'decoys' in the experiment, the lobsters were placed in these plastic bags. These live lobster decoys could enter and exit holes in the top shelter block or brick. They therefore presented a visual and perhaps auditory cue for experimental lobsters, but they were physically isolated and could transmit no chemical cue outside the bag. A plastic bag enveloped the top of each shelter in all the arenas to control for any potential bias created by the presence of the plastic bag. The bags were periodically checked for leaks, but none occurred.

The position of each treatment within the test tanks was changed 3 times to avoid any position artifacts. Once the appropriate experimental conditions were established, we released a single, well-fed test lobster into the center of each tank just prior to sunset. Preliminary trials revealed that $<10 \%$ of the individuals changed their choice of shelter after 24,36 , and $48 \mathrm{~h}$. Therefore, each trial was run for $24 \mathrm{~h}$, after which we recorded the position of the test lobster in each tank. These individuals were then removed and a new test subject added to the tank.

Testing for artifacts: To test for possible artifacts caused by differences in the biomass or size of lobsters used in the head tanks to supply the chemical effluent in our formal tests, we ran 3 more experiments. In the first set of tests ('Biomass Effect' trial), the biomass of the EBJ in the head tank creating the chemical signal for the EBJ trials was increased by an order of magnitude (from ca $15 \mathrm{~g}$ in the formal trials to ca $125 \mathrm{~g}$ ) in 20 replicate runs. If EBJ responded differently in this test than in the formal trial, then biomass probably plays a role in the detection of chemical cues by small lobsters and may confound our results.

For the second bias test ('Subadult Cue' trial), 6 subadult Iobsters ( 40 to $70 \mathrm{~mm} \mathrm{CL}$; ca $450 \mathrm{~g}$ ) were placed in the head tank that dispensed the chemical 
cue and tested with EBJ as the focal animals; 35 replicates were completed. If EBJ responded differently in this test compared with the formal tests or the Biomass Effect test, then we would suspect that later ontogenetic stages produce a chemical signal that earlier stages can detect but do not themselves produce.

The third bias test ('EBJ Cue' trial) is essentially the reverse of the Subadult Cue trial. In this case, $125 \mathrm{~g}$ of EBJ were placed in the head tanks to provide a chemical cue, and subadult lobsters were tested in the experiment. We ran 25 replicates of this experiment. If subadults responded to EBJ cues as well as others, then aggregation would result from a response to some chemical signal common to all lobster stages, not just those produced by large lobsters. In addition, if subadults responded to the effluent produced by $125 \mathrm{~g}$ of EBJ, it would indicate that variation in the biomass of lobsters in the header tank among treatments was not responsible for any differences in treatment effects. Alternatively, if subadults did not respond to the EBJ signal but did respond to cues from larger lobsters, then their response was specific to cues released by similar-sized conspecifics.

These laboratory data were analyzed using loglinear goodness of fit tests ( $G$ statistic) run separately for each lobster size class, since the shelter size and source of the chemical cues tested differed slightly among the experiments for each size class. Whether we were analyzing data for EBJ, juveniles, or subadults, the critical test was whether the frequency of shelter occupancy differed significantly among the shelter only, shelter + chemical cue, or shelter + decoys treatments.

Field tests of aggregation and den-type effects on mortality. The chief objective of this field experiment was to evaluate whether aggregation in or occupancy of specific dens affects the relative rate of mortality of juvenile lobsters of different sizes. We tethered individual lobsters belonging to 1 of 3 ontogenetic stages in natural habitats under 1 of 3 experimental conditions: (1) single lobster tethered in an unoccupied natural shelter that had been recently occupied (i.e. a known lobster den; 'Single-Unoccupied' treatment), (2) 3 lobsters of similar size tethered together in a natural crevice that was not known to have been occupied by lobsters ('Triple-Unoccupied' treatment), and (3) a single lobster tethered in an occupied natural shelter together with a group ( 3 to 6) of similar-sized, naturally aggregated lobsters ('Single-Occupied' treatment).

If aggregation reduces mortality, then we expected that more of the focal lobsters would be killed in the Single-Unoccupied treatment than in the Triple-Unoccupied treatment. If specific crevices are chosen by lobsters as dens because they afford better shelter from predators, then we predicted that mortality would be lower in the Single-Occupied treatment (where a sin- gle lobster is tethered in an existing den amidst other aggregated lobsters) as compared with the TripleUnoccupied treatment.

Experimental trials: Our experiments were conducted at 2 distant locations on the North Island of New Zealand: the first at Inner Table Top Reef in the Cape Rodney-to-Okakari Point Marine Reserve near Leigh, about $90 \mathrm{~km}$ north of Aukland (April to May 1995) and the second $560 \mathrm{~km}$ further south at Point Gordon on the Miramar Peninsula in Wellington Harbor (May 1995 to February 1996). Early benthic-stage juvenile lobsters were tethered at both the Leigh and Wellington sites; juvenile and subadult lobsters were tethered only at the Wellington site. There was no significant difference in the mortality rate of EBJ within treatments among sites $\left(\chi^{2}=0.61 ; \mathrm{df}=1 ; \mathrm{p}=0.44\right)$, so we did not distinguish results among sites in our final analyses.

Early benthic-stage juveniles were collected from crevice collectors, held in the laboratory for 1 mo or less, and then tethered to bricks with a $25 \mathrm{~cm}$ long strand of $1.8 \mathrm{~kg}(4 \mathrm{lb})$ test monofilament. Early benthic stage juveniles typically dwell in small holes, and so they were tethered to bricks so that they could withdraw into one of ten $1 \mathrm{~cm} \times 10 \mathrm{~cm}$ deep holes in each brick. They were fastened to the monofilament by forming a loop in the line, which was tightened around the cephalothorax between the 3ra and 4th pairs of legs, and also glued (cyanoacrylate gel glue) to the dorsal surface of the cephalothorax. The other end of the line was tied through a hole in the brick. Early benthic-stage juveniles assigned to the 2 solitary lobster treatments were tied to one of the center holes in the bricks, and 2 additional EBJ were tied to 2 of the outer holes in the bricks to create the Triple-Unoccupied lobster treatment.

Juvenile and subadult lobsters were collected by divers and generally held in the laboratory for $<1 \mathrm{mo}$, although 1 group was held in captivity for nearly a year. Mortality rates for these 2 groups were nearly identical ( $22 \%$ vs $30 \%$ after 48 h), so we did not differentiate among them in our final analysis. These larger lobsters were also tethered to bricks singly or in groups of 3 , but unlike the EBJ, the juveniles and subadults could not withdraw inside the brick holes. The brick simply anchored the lobsters in place in the desired natural crevice. We also used heavier $5.4 \mathrm{~kg}$ (12 lbj test and longer $(50 \mathrm{~cm})$ monofilament tethers for juvenile and subadult lobsters.

Tethered lobsters were held for a few hours or overnight in the laboratory to check for initial mortality or escapes and then outplanted at 5 to $10 \mathrm{~m}$ depth into natural crevices on rocky reefs. We mapped the position of each tether location so that we could easily relocate them. Small lobsters are generally killed faster 
than large lobsters, so the duration of each tethering trial varied with lobster size to ensure a measurable response. We revisited each EBJ tethering location after 12 and $24 \mathrm{~h}$, each juvenile lobster tethering location after 24 and $48 \mathrm{~h}$, and each subadult tethering location after 48 and $96 \mathrm{~h}$, and recorded the condition of each tethered lobster.

We used log-linear model analysis (G-statistic with William's correction factor) to determine whether mortality (presence or absence of a tethered individual) differed significantly among the 3 treatment conditions (i.e. Single-Unoccupied, Single-Occupied, and TripleUnoccupied). The tethering experiments conducted on the 3 different ontogenetic stages of lobsters differed in duration and in the way that the brick was used; either as a shelter (EBJ) or simply as a tethering post (juveniles and subadults). Because of the inherent differences in these experimental procedures, these data sets were analyzed separately for each ontogenetic stage of lobsters. The key statistical comparisons were among treatments (single-unoccupied, single-occupied, triple-unoccupied) within an ontogenetic grouping. When we analyzed the data we included only data for 1 observation period per size class: $24 \mathrm{~h}$ for EBJ, $24 \mathrm{~h}$ for juveniles, and $96 \mathrm{~h}$ for subadults. These time periods were chosen because they best satisfied the cell size assumptions of the log-linear tests. Furthermore, when lobsters are tethered together in groups, the results for more than 1 individual can be recorded, but data from only 1 individual should be analyzed to preserve independence among replicates. We chose a priori to use only the data from the lobsters tethered in the center of each group in our analyses.

Testing for artifacts: We also conducted 2 experiments to test for possible bias in our tethering results (Peterson \& Black 1994). Most of the lobsters we used in these experiments were collected in the field and tethered within a few days, but some of the subadult lobsters had been held in the laboratory for a few months before being tethered. Therefore, our first test of possible tethering bias was to determine whether holding lobsters in the laboratory for a few months affected their relative rate of survival. Subadult lobsters held in the laboratory for at least a month were tethered in dens with other naturally occurring lobsters. The results of these tethering trials were compared with results for lobsters that were tethered immediately after capture in the field; both sets of lobsters were exposed to the same treatment condition (i.e. 'Single-Occupied' treatment). The results for these 2 groups were nearly identical: $70 \%$ of the laboratoryheld lobsters and $78 \%$ of the field-caught lobsters survived tethering for $96 \mathrm{~h}$.

The second test of bias was designed to determine if escapes from the tethers varied among sizes or differed when lobsters were tethered alone or in groups of 3 . We observed lobsters tethered alone and in groups of 3 and recorded the frequency of escape of EBJ and subadult lobsters in the laboratory for 24 and $96 \mathrm{~h}$ (respectively) to document escape rates from tethers. None of the EBJ escaped. The escape rate for subadults that were triple-tethered, however, was unexpectedly high at nearly $25 \%$ versus $<5 \%$ for singletethered subadult lobsters. It is also possible that lobsters tethered in triplets might become entangled and thus more susceptible to predation. Fortunately, if either of these sources of bias occurred (i.e. higher escape or mortality of triple-tethered lobsters) it would not alter interpretation of our key results because in the field, we had the highest survival or retention (see 'Results') of lobsters in the treatment where lobsters were tethered in triplicate. We also do not know whether our use of brick anchors somehow increased predator visitation. However, if it did, the effect was consistent across treatments and so would not result in a differential bias among treatments.

\section{RESULTS}

\section{Ontogenetic changes in the spatial distribution of natural populations}

Large-scale observations of lobster distributions

Our surveys of lobster aggregation patterns in $25 \mathrm{~m}^{2}$ subplots at 4 locales scattered along the east coast of New Zealand revealed a distinctive difference in the pattern of aggregation between EBJ and both juvenile and subadult lobsters (Fig. 3). Early benthic stage juvenile lobsters were most often found alone or in low numbers of $<4$ individuals per $25 \mathrm{~m}^{2}$ subplot. In contrast, juveniles and subadults were often clumped and most aften exceeded 10 individuals per $25 \mathrm{~m}^{2}$ subplot (Fig. 3)

Lobster distribution and settlement at Gisborne Harbor

Up to 13 Jasus edwardsii EBJ were found dwelling in holes on a single $6 \mathrm{~m}^{2}$ rock face (a density of $2.2 \mathrm{~m}^{2}$ ) along the rock wall in Gisborne Harbor, but their average density over the 29 mo period was only $0.17 \mathrm{~m}^{2}$, or about 1 EBJ per rock face. During the 29 mo period, we observed 595 postlarvae and EBJ, and during the last 10 mo of that time we tagged a subsample of $42 \mathrm{EBJ}$ and noted the subsequent positions of tagged individuals on the rock wall for $2 \mathrm{~d}$ after tagging. Most (77\%) of the tagged EBJ were observed again during the next $2 \mathrm{~d}$, and most of them ( 77 to $81 \%$ ) had not moved from 


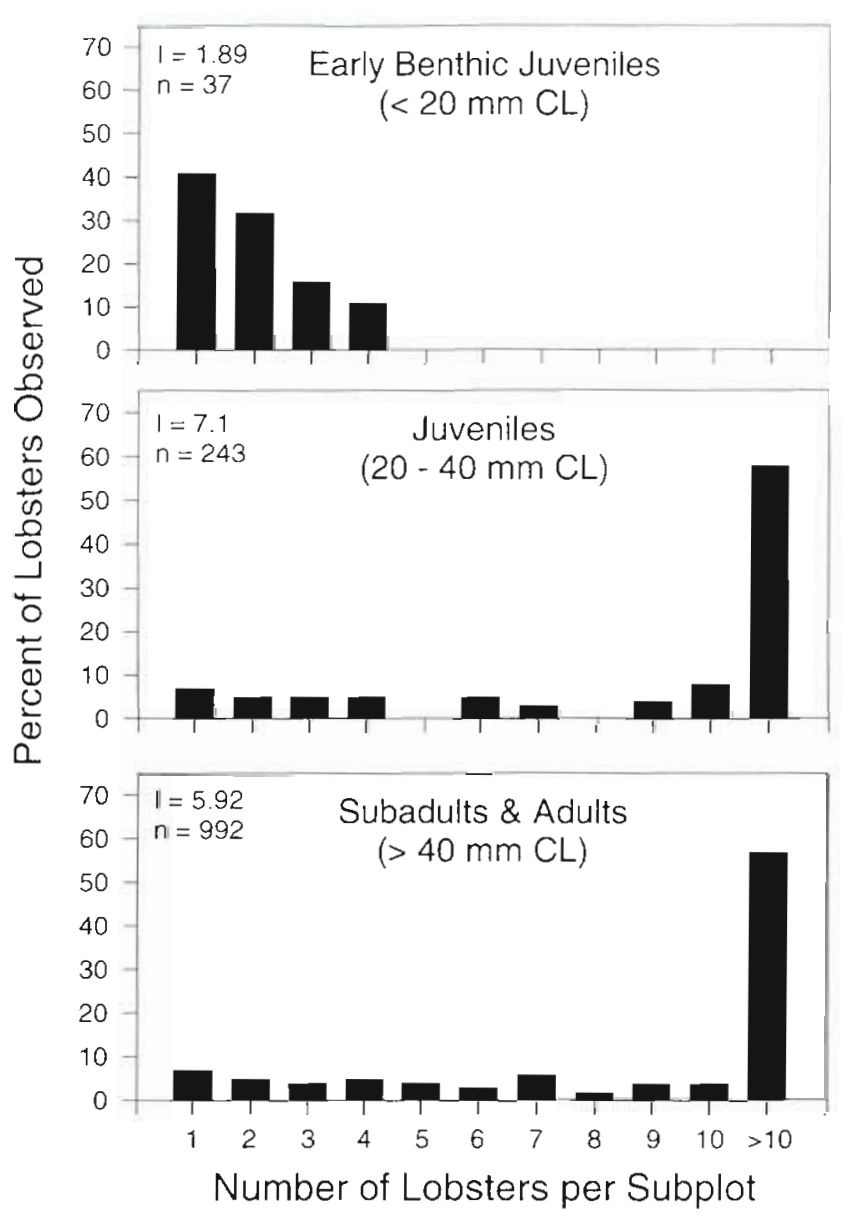

Fig. 3. Three frequency distributions describing the percentage of lobsters of 3 ontogenetic stages that were observed in different group sizes within $80025 \mathrm{~m}^{2}$ subplots sampled at 4 locations along the New Zealand east coast. The Index of Dispersion (I), or variance/mean ratio, for the data for the 3 ontogenetic stages is shown in each panel; all values indicate significantly clumped distributions

their original den. The few EBJ that had moved were found close by, typically less than $20 \mathrm{~cm}$ away (mean = $13 \mathrm{~cm}$ ), although 1 individual had moved to a new den $2 \mathrm{~m}$ away overnight.

Our long term (29 mo) surveys describing the spatial distribution of EBJ Jasus edwardsii indicate that the lobsters were distributed randomly within holes on a rock wall in Gisborne Harbor. The distribution of EBJ yielded a Standardized Morisita's Index between - 0.5 and 0.5 on 21 of 29 monthly surveys (Fig, 4), indicating that the distribution of EBJ was usually random. On the 8 occasions when the index exceeded 0.5 , the values clustered very near this minimum significance value. A chi-square test (with Yates' correction) of this distribution of significant and non-significant index values $\left(\chi^{2}=2.15 ; \mathrm{df}=1 ; \mathrm{p}=0.1428,1-\beta=0.29\right)$ showed that 8 occurrences of a significant index value in 29 instances is not significantly different from random expectations.
A weak positive correlation $(r=0.41$; $\mathrm{df}=29 ; \mathrm{p}=$ 0.03 ) existed between monthly postlarval settlement density on artificial collectors and the Standardized Morisita's Index describing clumping of EBJ on the rock wall (Fig. 4). This indicates that EBJ become more aggregated at the scale of a rock face $\left(6 \mathrm{~m}^{2}\right)$ when settlement is highest, but as noted above, the EBJ were never highly aggregated even when their densities were at their maximum.

Using the more detailed surveys conducted during the last 10 mo of the study and Hill's TTLQV method, we again found no evidence that Jasus edwardsii EBJ aggregate at scales ranging from $2 \mathrm{~m}^{2}$ to $20 \mathrm{~m}^{2}$ (Fig. 5 ). Interpretation of peaks in the variance plots produced using Hill's method are admittedly subjective, but evidence for clumping is usually limited to sharp peaks quite distinct from the mean variance (Ludwig \& Reynolds 1988). The variance peaks in the TTLQV plot we produced were low and poorly defined across the spatial scales we examined, thus indicating a random distribution. We tried to investigate aggregation at even smaller spatial scales, down to $0.2 \mathrm{~m}^{2}$, but EBJ occurred so infrequently at scales $<2 \mathrm{~m}^{2}$ that the analysis could not be run.

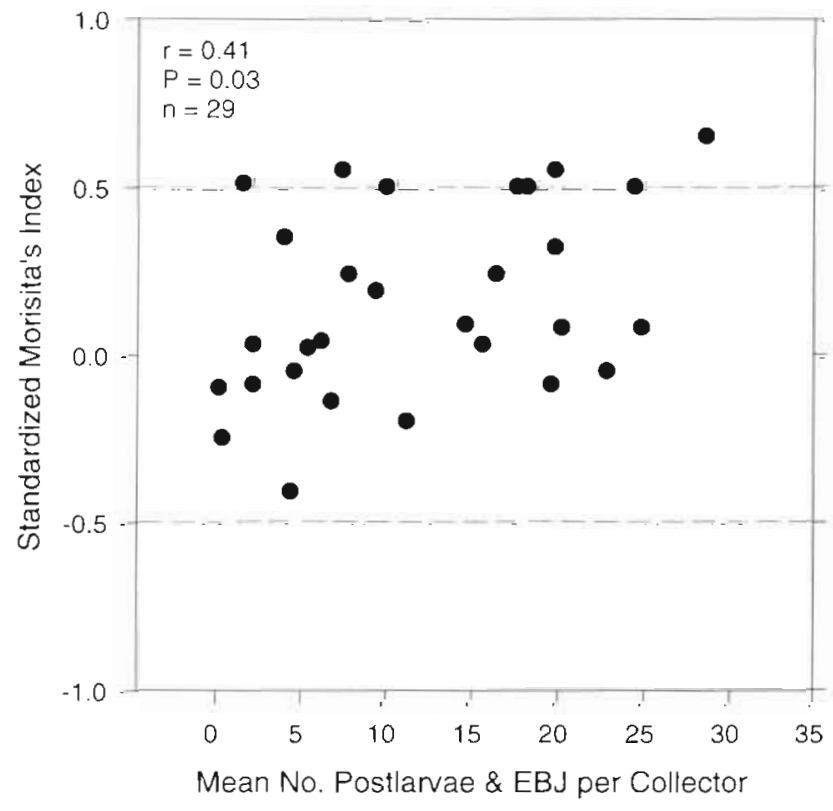

Fig. 4. Relationship between the mean monthly settlement of postlarvae and EBJ on collectors in Gisborne Harbor ( $x$-axis) and the degree of clumping (Standardized Morisita's Index; $y$-axis) by newly settled pueruli and EBJ during 29 monthly surveys. Months when Standardized Morisita's Index exceeded \pm 0.5 (indicated by hatched lines in the graph) indicate that the distribution of settlers was significantly different from random. The results of a correlation analysis testing whether settlement magnitude was significantly correlated with settler distribution are also shown 


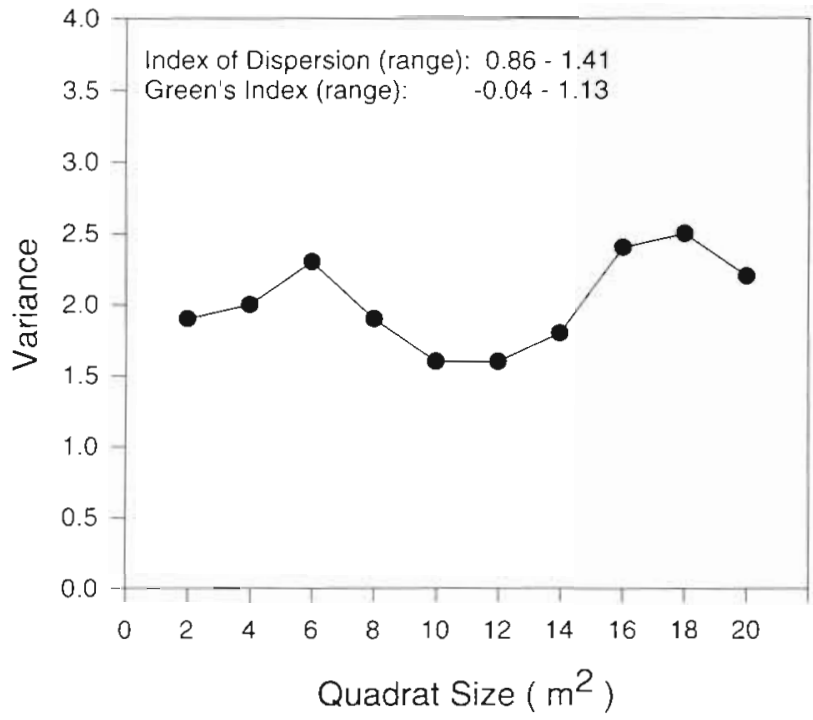

Fig. 5. Results of short-term surveys exarnining the spatial distribution of postlarvae and EBJ dwelling in holes on a rock face in Gisborne Harbor. On the $y$-axis is a variance estimate determined using Hill's Two Term Local Quadrat Variance Method (TTLQV), which permits examination of the pattern of dispersion of settlers across spatial scales ranging from $2 \mathrm{~m}^{2}$ to $20 \mathrm{~m}^{2}$ ( $\mathrm{x}$-axis). Pronounced peaks in the values, which would indicate clumping of settlers at the corresponding quadrat size, are not present, indicating a random distribution of lobsters. The Index of Dispersion $(I)$ and Green's Index of Dispersion were also calculated for each sample month and the ranges of those values over the 10 mo period are also shown

\section{Laboratory tests of aggregation cues}

In laboratory tests of aggregation cues, subadults aggregated using chemical cues released by similarsized individuals, whereas lobsters at earlier ontogenetic stages did not. Jasus edwardsii EBJ and juveniles responded similarly to our 3 experimental treatments (Fig. 6). Early benthic stage juveniles ( $\mathrm{n}=48 ; G=1.87$; $\mathrm{df}=2 ; \mathrm{p}=0.39)$ and juveniles $(\mathrm{n}=24 ; G=2.10 ; \mathrm{df}=2$; $\mathrm{p}=0.35$ ) did not seek shelters with live decoys or respond to potential chemical cues from similar-sized conspecifics. In contrast, subadult $J$, edwardsii were attracted to shelters supplied with water conditioned by either similar-sized conspecifics $(G=13.16$; $\mathrm{df}=2$; $p=0.001 ;$ Fig. 6$)$ or EBJ $(G=14.48 ; \mathrm{df}=2 ; \mathrm{p}=0.001)$.

The lack of a response by EBJ to the chemical effluent treatment was not due to a low biomass of EBJ in the head tank dispensing the effluent. When we boosted the biomass of EBJ in the head tank by an order of magnitude to approach the biomass in the juvenile and subadult trials, the result remained unchanged. Early benthic stage juveniles still chose shelters without regard to the experimental treatment ( $\mathrm{n}=35 ; G=0.20 ; \mathrm{df}=2 ; \mathrm{p}=0.90$ ). In contrast, this same high biomass of EBJ in the head tank elicited a signifi-

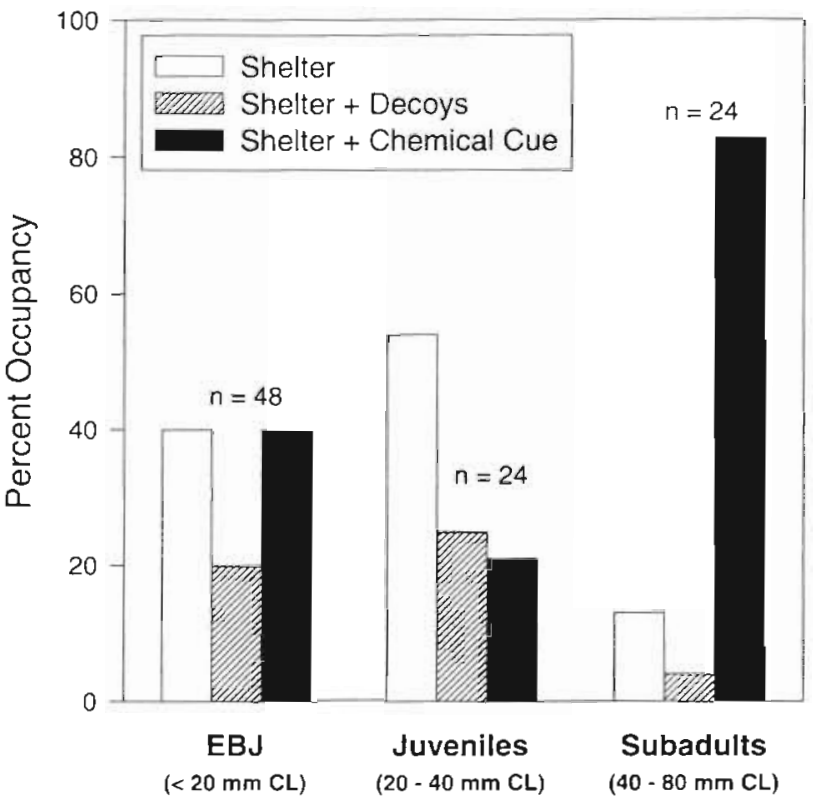

Fig. 6. Results of the laboratory study that show the percentage of lobsters in each of 3 ontogenetic stages that chose 1 of 3 possible shelter treatments: (1) shelter alone (Shelter treatment), (2) shelter with lobster decoys, but no chemical cues (Shelter + Decoy treatment), or (3) shelter supplied with the chemical scent of conspecifics (Shelter + Chemical Cue treatment)

cant response by subadults ( $\mathrm{n}=25 ; G=14.48$; $\mathrm{df}=2 ; \mathrm{p}$ $<0.001$ ). Early benthic juveniles also did not respond to the same chemical cues to which the subadult lobsters reacted so strongly. Early benthic stage juveniles were just as apt to dwell in control shelters, shelters with decoys, and in shelters where dispensed water was from head tanks holding subadult lobsters ( $\mathrm{n}=19 ; \mathrm{G}=$ 0.33 ; df $=2 ; \mathrm{p}=0.85$ ).

\section{Field tests of aggregation and den-type effects on mortality}

The relative mortality of tethered Jasus edwardsii depended on individual size and the tethering treatment. Aggregation among the subadult tethered lobsters improved the focal individual's chance of survival. Solitary EBJ survived just as well (26\% alive after $24 \mathrm{~h}$ ) as those that were aggregated (24\% alive after $24 \mathrm{~h}$; Fig. 7). However, EBJ tethered singly in a crevice already occupied by larger lobsters survived better ( $52 \%$ alive after $24 \mathrm{~h}$ ) than EBJ tethered alone or in groups of 3 in an unoccupied crevice $(G=6.025 ; \mathrm{p}=$ $0.05 ; \mathrm{df}=2$; Fig. 7). Juvenile lobsters survived equally well in all 3 treatments $G=3.40 ; \mathrm{p}=0.18$; $\mathrm{df}=2$; Fig. 7). Only subadult lobsters gained an appreciable survival advantage when they were aggregated $(G=$ 

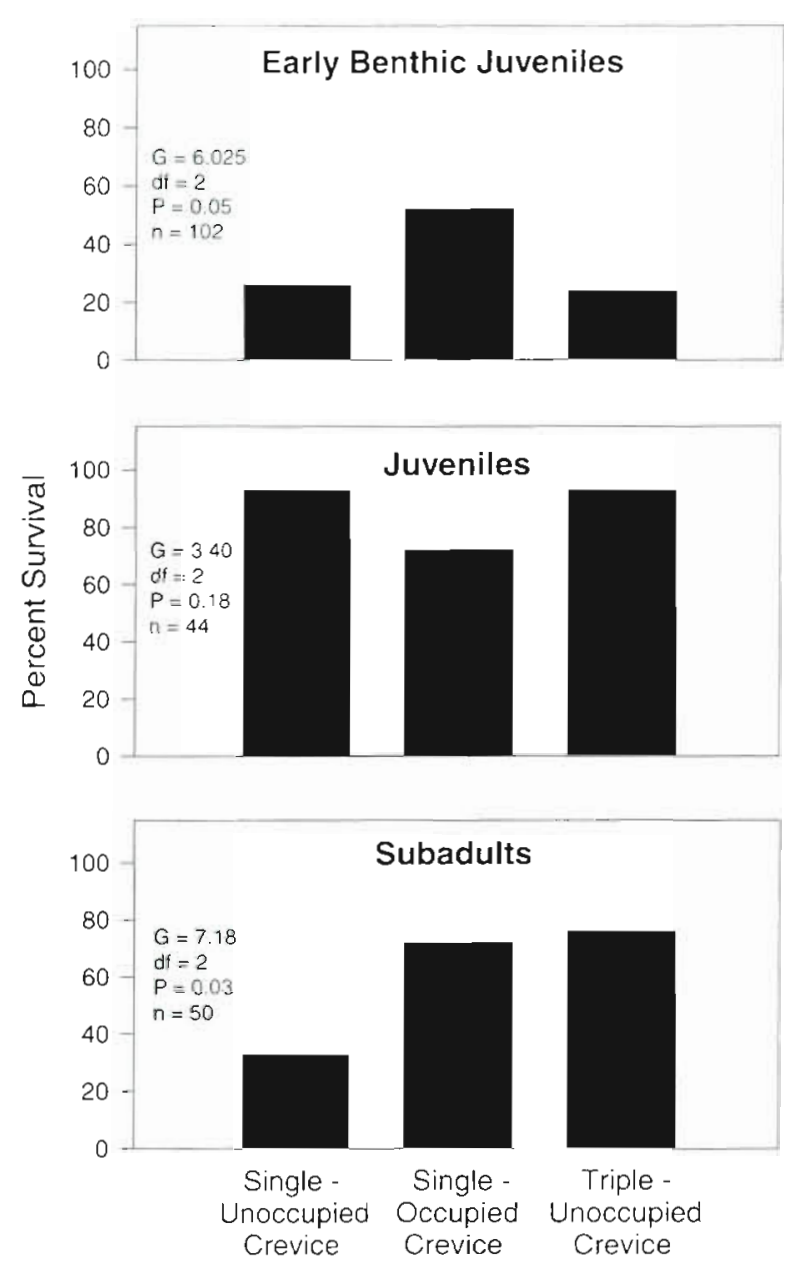

Fig. 7. Relative survival (percent survival) of individual lobsters in 1 of 3 ontogenetic stages tethered in the field in 1 of 3 treatment conditions: (1) a single individual tethered alone in an unoccupied crevice (Single-Unoccupied treatment), (2) a single individual tethered in a crevice already occupied by other lobsters (Single-Occupied treatment), and (3) 3 individuals tethered together in an unoccupied crevice (TripleUnoccupied treatment). The results of the log-linear tests are shown in each panel

7.18; $p=0.03 ; \mathrm{df}=2$; Fig. 7). The survival of subadult lobsters more than doubled when they were tethered with other subadults, whether they were in an occupied den with naturally occurring lobsters or in an unoccupied den with tethered lobsters.

\section{DISCUSSION}

\section{Ontogenetic patterns of aggregation}

Changing habitat requirements and associated changes in local ecological conditions experienced during a species' different developmental stages may select for ontogenetic changes in aggregation, sometimes creating situations where juveniles are solitary and adults are aggregated. For example, the smallscale spatial distributions of planktonic larvae are often an unpredictable consequence of physical dynamics in the water column. Following the planktonic period, specific settlement requirements and the distribution of suitable habitat patches result in aggregations of settlers. Some invertebrates even settle aggregatively in response to the chemical cues of kin (Keough 1984, Connel 1985). Thereafter, differences in postsettlement growth and survival among settlement sites can further concentrate older individuals into discrete clumps. On rocky shores, for example, crevices shield animals from the crush of waves, resulting in aggregations of bivalves, gastropods, and barnacles. Patches are created on a smaller scale wherever small holes or depressions on rocky substrates offer species such as bryozoans, barnacles, or crabs refugia from fish predators (Keough \& Downes 1982, Eggleston \& Armstrong 1995, Butler et al, 1997). Yet this type of aggregation, dictated by the distribution of habitat and so common among marine benthic invertebrates, is not a consequence of ontogenetic changes in social behavior such as that observed in spiny lobsters.

The early life history of the shallow-water spiny lobster has now been sufficiently well studied that a consistent ontogenetic pattern in social behavior is emerging Spiny lobster postlarvae appear to settle randomly within suitable natural habitats and are often sparsely distributed, as are the early benthic stage juveniles that dwell solitarily in crevices or vegetation (e.g Panulirus argus: Marx \& Herrnkind 1985, Herrnkind \& Butler 1986, 1994, Field \& Butler 1994, Butler et al. 1997; P. cygnus: Jernakoff 1990; P. japonicus: Yoshimura \& Yamakawa 1988, Norman et al, 1994; P. guttatus: Sharp et al. 1997; P. interruptus: Serfling \& Ford 1975; and others). As they grow larger, the juveniles become increasingly social and aggregate in dens. The gregarious subadults and adults of most species reside in habitats different than that of EBJ (e.g. P. argus, $P$. cygnus), or in larger den structures within the same habitat (e.g. J. edwardsii). The adults and subadults of a few species are known to be attracted by chemical cues released by conspecifics ( $P$. interruptus: ZimmerFaust et al. 1985, Zimmer-Faust \& Spanier 1987; $P$. argus: Ratchford \& Eggleston 1998)

This study indicates that aggregation occurs primarily among larger lobsters because the response to chemicals released by conspecifics does not develop until adolescence. We found that EBJ and juveniles do not respond to chemical effluents produced by larger, subadult lobsters. In contrast, subadults exhibit a striking aggregative response to chemical cues produced by other lobsters. We also provide new evidence that 
the resultant aggregation of subadult lobsters confers on participants an ecological advantage (better protection from predators) that is not available to smaller, earlier life stages. Aggregation is beneficial for subadult and adult lobsters (Eggleston et al. 1990 and this study), but EBJ lobsters, even groups of them, are ineffective in defending themselves against predators. Their best defense is to reduce encounter rates with potential predators, and they do so by limiting their movement and being cryptic (Butler et al. 1997).

Our tethering results also suggest that EBJ Jasus edwardsii may survive better if they dwelled in dens with groups of large conspecifics, which presumably fend off potential predators. However, this result may be more of an experimental curiosity than an ecologically significant finding. In nature, the various spiny lobster life stages often live in different habitats or seek different-sized dens, so cohabitation by various ontogenetic stages is often not a possibility.

\section{Ecological processes promoting aggregation}

Our tethering results do not support the hypothesis that lobster aggregations occur in specific dens that offer extraordinary protection from predators. The key test of this hypothesis is a comparison of the results where single lobsters were tethered in existing dens alongside several resident lobsters (Single-Occupied treatment) versus the situation where 3 lobsters were tethered together in a crevice that was previously unoccupied (Triple-Unoccupied treatment). The results did not differ significantly between these 2 treatments for any of the lobster size classes we tested. Therefore, differential survival among potential den sites does not explain the observed patchy distribution of lobsters. This result leaves the question of why certain dens are occupied more often than others unanswered (Herrnkind \& Lipcius 1985, MacDiarmid 1994). A den's proximity to food, migration routes, or sources of settlers are plausible explanations for unusually high residency in some dens.

The residual 'scent' of lobsters that recently occupied the den would also be an attractant to other lobsters and offers another explanation for the more persistent use of some dens. In some regions, such as the Hawaiian islands (Parrish \& Polovina 1994) and the Florida Keys (Butler \& Herrnkind 1997, Herrnkind et al. 1997), suitable dens for large lobsters are scarce. Under such circumstances, there may be competition for limited dens, or there could be cooperative use of them (Eggleston et al. 1990) if the dens are large enough to permit multiple occupants. It has been suggested that the evolution of social aggregation of Panulirus argus may have developed as a means of locat- ing suitably-sized crevices where crevices are sparse and patchily distributed (Childress \& Herrnkind 1996). $P$. argus make nightly forays far from their dens to feed in adjacent seagrass and rubble habitats, so chemical cues emanating from den sites occupied by conspecifics may serve as a beacon that guides individuals to a den more quickly, thus reducing unnecessary exposure to predators.

The conditions typically experienced by Jasus edwardsii may, however, be different. Potential den sites appear to be much more abundant among the rocky reefs skirting the New Zealand shoreline. In addition, juvenile $J$. edwardsii do not engage in the same nightly, long-distance foraging migrations across open habitat as the tropical Panulirus argus. Instead, $J$. edwardsii eat the abundant prey (e.g. mussels, urchins) concentrated on the high-biomass temperate reefs surrounding their dens (A. MacDiarmid pers. obs.). These observations and our experimental results suggest that the response of juvenile $J$, edwardsii to the chemical signals of conspecifics may have evolved for the purpose of concentrating individuals in defensive pods, rather than as a means of locating shelter from afar, as is the case for the Caribbean spiny lobster This may be a particularly effective strategy for $J$. edwardsii, which is morphologically more robust and more aggressive than its Caribbean counterpart.

Both of these hypotheses concerning the evolution of social communication in spiny lobsters and its adaptive significance have theoretical support, although the development of chemical signals for the purpose of group defense may offer a more rapid evolutionary trajectory. Theoretical studies of social selection and the evolution of animal signals indicate that behavioral responsiveness to conspecific signals is subject to runaway selection (Tanaka 1996). These theories are typically tendered as explanations for interspecific aggressive interactions, but the necessary conditions are applicable to the chemical signaling and social aggregation scenario that occurs in spiny lobsters. Theory suggests that the evolution of social behavior converges most rapidly on a single genetic equilibrium when receivers benefit from the signal and when the signal provides reliable information about the signaler (Tanaka 1996). In the case of Jasus edwardsii, both the individuals that release the chemical cue (signalers) and those that are attracted to it (receivers) benefit from the social aggregation that the signal promotes, because mortality is lower when lobsters form groups.

Changes in the propensity of spiny lobsters to aggregate as they age is but one of many ontogenetic shifts that occur as these animals grow from the EBJ stage to adulthood. Their choice of shelters and even habitats changes as they grow. Their coloration changes, usually rendering them more cryptic in their new habitat (Butler 
et al. 1997). Their activity patterns and rates of movement also change as they age (Childress \& Herrnkind 1994), and their diet is altered, perhaps reflecting the lobster's change in habitat use and morphology (Herrnkind et al. 1988, Wolfe \& Felgenhauer 1991). For species with complex life cycles, this suite of dramatic, interrelated ontogenetic changes reflects what must be a profound shift in the character of the environment and selective pressures that affect the success of various developmental stages as individuals approach maturity.

Acknowledgements. This research was supported by a National Science Foundation award (INT-9418306), a New Zealand National Institute of Water and Atmospheric Research (NIWA) Visiting Scientist Fellowship to M.J.B., and a New Zealand Ministry of Research, Science, and Technology award (No. 94-NIW-10-067) to A.B.M. We are grateful for the logistical support provided by NIWA and the University of Auckland's Leigh Marine Laboratory. Comments by W. Herrnkind, M. Childress, and R. Grossberg on earlier versions of this manuscript are also appreciated.

\section{LITERATURE CITED}

Atema J, Cobb JS (1980) Social behavior. In: Cobb JS, Phillips BF (eds) The biology and management of lobsters, Vol I. Academic Press, New York, p 409-450

Berrill M (1975) Gregarious behavior of juveniles of the spiny lobster Panulirus argus (Crustacea: Decapoda). Bull Mar Sci 25:515-522

Bertram BCR (1978) Living in groups: predators and prey. In: Krebs JR, Davies NB (eds) Behavioral ecology: an evolutionary approach. Blackwell Scientific Pub, Oxford, p 64-96

Booth JD (1979) Settlement of the rock lobster, Jasus edwardsii (Decapoda: Palinuridae), at Castlepoint, New Zealand. NZ J Mar Freshw Res 13:395-406

Booth JD, Bowring LD (1988) Decreased abundance of the puerulus stage of the rock lobster Jasus edwardsii, at Kaikoura, New Zealand (Note) Castlepoint, New Zealand. NZ J Mar Freshw Res 22:613-616

Booth JD, Tarring SC (1986) Settlement of the red rock lobster, Jasus edwardsii, near Gisborne, New Zealand. NZ J Mar Freshw Res 20:291-297

Booth JD, Carruthers AD, Bolt CD, Stewart RA (1991) Measuring depth of settlement in the red rock lobster, Jasus edwardsij. NZ J Mar Freshw Res 25:123-132

Butler MJ IV, Herrnkind WF (1997) A test of recruitment limitation and the potential for artificial enhancement of spiny lobster (Panulirus argus) populations in Florida. Can J Fish Aquat Sci 54:452-463

Butler MJ IV, Herrnkind WF, Hunt JH (1997) Factors affecting the recruitment of juvenile Caribbean spiny lobsters dwelling in macroalgae. Bull Mar Sci 61:3-19

Catterall CP, Poiner IR (1983) Age- and size-dependent patterns of aggregation in the tropical gastropod Strombus luhuanus. Mar Biol 77:171-182

Childress MJ, Hernakind WF (1994) The behavior of juvenile Caribbean spiny lobster in Florida Bay: seasonality, ontogeny, and sociality. Bull Mar Sci 54:819-827

Childress MJ, Herrnkind WF (1996) The ontogeny of social behaviour among juvenile Caribbean spiny lobsters. Anim Behav 51:675-687

Cobb JS (1981) Behavior of the Western Australian spiny lob- ster, Panulirus cygnus (George) in the field and laboratory. Austr J Mar Freshw Res 32:399-409

Connell JH (1985) The consequences of variation in initial settlement vs post-settlement mortality in rocky intertidal communities. J Exp Mar Biol Ecol 93:11-45

Dukas R, Clark CW (1995) Searching for cryptic prey: a dynamic model. Ecology 76:1320-1326

Eggleston DB. Armstrong DA (1995) Pre-and post-settlement determinants of estuarine Dungeness crab recruitment. Ecol Monogr 65:193-216

Eggleston D, Lipcius R, Coba-Centina L, Miller D (1990) Shelter scaling regulates survival of juvenile spiny lobster, Panulirus argus. Mar Ecol Prog Ser 62:79-88

Field JM, Butler MJ IV (1994) The influence of temperature, salinity, and postlarval transport on the distribution of juvenile spiny lobsters, Panulirus argus (Latreille, 1804) in Florida Bay. Crustaceana 67:26-45

Glaholt RD (1990) Social behavior and habitat use of captive juvenile spiny lobster, Panulirus argus (Latreille, 1804) (Decapoda, Palinuridae). Crustacea 58:200-206

Harvey PH, Greenwood PJ (1978) Anti-predator defence strategies: some evolutionary problems. In: Krebs JR, Davies NB (eds) Behavioral ecology: an evolutionary approach. Blackwell Scientific Pub, Oxford, p 129-154

Heffner RA, Butler MJ IV, Reilly CK (1996) Pseudoreplication revisited. Ecology 77:2558-2562

Herrnkind WF, Butler MJ IV (1986) Factors regulating postlarval settlement and juvenile microhabitat use by spiny lobsters, Panulirus argus. Mar Ecol Prog Ser 34:23-30

Herrnkind WF, Butler MJ IV (1994) Settlement of spiny lobster, Panulirus argus (Latreille, 1804), in Florida: pattern without predictibility? Crustaceana 67:46-64

Herrnkind WF, Lipcius RN (1989) Habitat use and population biology of Bahamian spiny lobster. Proc Gulf Caribb Fish Inst 39:265-278

Herrnkind WF, Butler MJ IV, Tankersley RA (1988) The effects of siltation on recruitment of spiny lobsters, Panulirus argus. Fish Bull 86:331-338

Herrnkind WF, Jernakoff P, Butler MJ IV (1994) Puerulus and post-puerulus ecology. In: Phillips BF, Cobb JS, Kittaka J (eds) Spiny lobster management. Blackwell Scientific Press, Oxford, p 213-229

Herrnkind WF, Butler MJ IV, Hunt JH, Childress MC (1997) Role of physical refugia: implications from a mass sponge die-off in a lobster nursery in Florida. Mar Freshw Res 48: $759-769$

Hill MO (1973) The intensity of spatial pattern in plant communities. J Ecol 61:225-236

Hurlbert SH (1984) Pseudoreplication and the design of ecological field experiments. Ecol Monogr 54:187-211

Jernakoff P (1990) Distribution of newly settled western rock lobsters Panulirus cygnus. Mar Ecol Prog Ser 66:63-74

Kensler CB (1967) The distribution of spiny lobsters in New Zealand waters (Crustacea: Decapoda: Palinuridae). NZ J Mar Freshw Res 1:412-420

Keough MJ (1984) Kin-recognition and the spatial distribution of larvae of the bryozoan Bugula neritina (L.). Evolution 38:142-147

Keough MJ, Downes BJ (1982) Recruitment of marine invertebrates: the role of active larval choices and early mortality. Oecologia 54:348-352

Lavalli KL, Lawton P (1996) Historical review of lobster life history terminology and proposed modifications to current. schemes. Crustaceana 69:594-609

Lima SL, Dill LM (1990) Behavioural decisions made under the risk of predation: a review and prospectus. Can J Zool $68: 619-640$ 
Lipcius RN, Cobb SJ (1994) Introduction: ecology and fishery biology of spiny lobsters. In: Phillips BF, Cobb JS, Kittaka J (eds) Spiny lobster management. Blackwell Scientific Press, Oxford, p 1-30

Ludwig JA, Reynolds JF (1988) Statistical ecology. J Wiley and Sons, Inc, New York

MacDiarmid AB (1991) Seasonal changes in depth distribution, sex ratio, and size frequency of spiny lobster Jasus edwardsii on a coastal reef in northern New Zealand. Mar Ecol Prog Ser 70:129-141

MacDiarmid AB (1994) Cohabitation in the spiny lobster Jasus edwardsii (Hutton, 1875). Crustaceana 66:341-355

MacDiarmid AB, Hickey B, Maller RA (1991) Daily movement patterns of the spiny lobster Jasus edwardsiu (Hutton) on a shallow reef in northern New Zealand. J Exp Mar Biol Ecol 147:185-205

Major PF (1978) Predator-prey interactions in 2 schooling fishes, Caranx ignobilis and Stolephorus purpureus. Anim Behav 26:760-777

Marx JM, Hermkind WF (1985) Factors regulating microhabitat use by young juvenile spiny lobsters, Panulirus argus: food and shelter. J Crustac Biol 5:650-657

Milinski M. Parker GA (1991) Competition for resources. In: Krebs JR, Davies NB (eds) Behavioural ecology: an evolutionary approach. Blackwell Scientific Press, Oxford, $p$ 137-168

Myers JH (1978) Selecting a measure of dispersion. Environ Entomol 7:619-621

Norman CP, Yamakawa H, Yoshimura T (1994) Habitat selection, growth rate, and density of juvenile Panulirus japonicus (Von Siebold, 1824)(Decapoda, Palinuridae) at Banda, Chiba Prefecture, Japan. Crustaceana 66:366-383

Owen D (1980) Camouflage and mimicry, University of Chicago Press, Chicago, IL

Parrish FA, Polovina JJ (1994) Habitat thresholds and bottlenecks in production of the spiny lobster (Panulirus marginatus) in the northwestern Hawaiian islands. Bull Mar Sci 54:151-163

Peterson CH, Black R (1994) An experimentalist's challenge: when artifacts of intervention interact with treatments. Mar Ecol Prog Ser 111:289-297

Phillips BF, Booth JD (1994) Design, use, and effectiveness of collectors for catching the puerulus stage of spiny lobsters. Rev Fish Sci 2:255-289

Pitcher TJ (1992) Behavior of teleosts fishes, 2nd edn. Kluwer Academic Pub, Dordrecht

Pitcher TJ, Magurran AE, Winfield I (1982) Fish in larger schools find food faster. Behav Ecol Sociobiol 10:149-151

Editorial responsibility: Otto Kinne (Editor), Oldendorf/Luhe, Germany
Pulliam HR, Caraco T (1984) Living in groups: is there an optimal group size? In: Krebs JR, Davies NB (eds) Behavioural ecology: an evolutionary approach. Blackwell Scientific Press, Oxford, p 122-147

Ratchford SG Eggleston DB (1998) Size- and scale-dependent chemical attraction contribute to an ontogenetic shift in ontogeny. Anim Behav 56:1027-1034

Ritz DA (1994) Social aggregation in pelagic invertebrates. Adv Mar Biol 30:155-216

Serfling SA, Ford RF (1975) Ecological studies on the puerulus larval stage of the California spiny lobster Panulirus interruptus. US Nat Mar Fish Serv Bull 73:360-377

Sharp WC, Hunt JH, Lyons WG (1997) Life history of the spotted spiny lobster, Panulirus guttatus, an obligate reefdweller. Mar Freshw Res 48:687-698

Stoner AW, Ray M (1993) Aggregation dynamics in juvenile queen conch (Strombus gigas): population structure, mortality, growth, and migration. Mar Biol 116:571-582

Tanaka Y (1996) Social selection and the evolution of animal signals. Evolution 50:512-523

Tinbergen N, Impekoven M, Franck D (1967) An experiment on spacing-out as a defence against predation. Behaviour $28: 307-321$

Treisman $M$ (1975) Predation and the evolution of gregariousness. I. Models for concealment and evasion. Anim Behav 23:779-800

Trendall J, Bell S (1989) Variable patterns of den habitation by the ornate rock lobster, Panulirus ornatus, in the Torres Strait. Bull Mar Sci 45:564-573

Trivers R (1985) Social evolution. Benjamin and Cummings Publ, Menlo Park, CA

Wilson EO (1975) Sociobiology: the new synthesis. Harvard University Press, Cambridge, MA

Wolfe $\mathrm{SH}_{1}$ Felgenhauer BE (1991) Mouthpart and foregut ontogeny in larval, postlarval, and juvenile spiny lobster, Panulirus argus Latreille (Decapoda, Palinuridae). Zool Script 20:57-75

Yoshimura T, Yamakawa H (1988) Ecological investigations of settled puerulus and juvenile stages of the Japanese spiny lobster Panulirus japonicus at Kominato, Japan. J Crustac Biol 8:524-531

Zimmer-Faust RK, Spanier E (1987) Gregariousness and sociality in spiny lobsters: implications for den habitation. J Exp Mar Biol Ecol 105:57-71

Zimmer-Faust RK, Tyre JE, Case JF (1985) Chemical attraction causing aggregation in the spiny lobster. Panulirus interruptus, and its probable ecological significance. Biol Bull 169:106-118

Submitted: September 25, 1998; Accepted: May 26, 1999 Proofs received from author(s): October 25, 1999 